\title{
Videojuegos en seis escuelas de tiempo completo: puente entre lo sociocultural y lo didáctico pedagógico
}

\section{Video games in six full-time Primary Schools: A bridge between socio-cultural and didactic- pedagogical activities}

\begin{abstract}
Nancy Geymonat Vignolo
Master en Educación y Diploma en Educación, Universidad ORT Uruguay. Maestra en Educación Común. Maestra Dinamizadora del Plan CEIBAL, CEIP. Docente Orientador Educacional y Profesora de Informática en el Instituto de Profesores "Artigas". Profesora de Informática, CES.
\end{abstract}

Fecha de recibido: 17/02/2014

Fecha de aceptación: 11/06/2014

\section{Resumen}

Los videojuegos forman parte de las actividades lúdicas de los niños de la sociedad actual, quienes pueden pasar horas jugando con ellos y concentrarse intensamente en los mismos. Varios autores se han preguntado por qué no usarlos en la enseñanza. El programa de Educación Primaria señala que el juego debe ser desarrollado de manera intencional por los docentes como contenido y como estrategia metodológica importante.

En la evaluación del Plan CEIBAL los niños manifiestan que lo que más les interesa de las XO son los juegos. La investigación realizada en el año 2012 en seis escuelas de tiempo completo tuvo como objetivo indagar sobre el empleo de los videojuegos por parte de los docentes en las aulas de este tipo de escuelas. Se buscó obtener información sobre si en esas escuelas existe relación entre este tipo de actividades lúdicas y la enseñanza. En esos casos se indagaron los propósitos de los docentes al planificar actividades que los incorporaran y en qué escenarios tal cosa se llevaba a cabo.

El diseño de la investigación fue exploratorio y descriptivo. La metodología que se utilizó fue mixta, a través de una muestra intencional compuesta por seis escuelas de tiempo completo de Montevideo de contextos diferentes. Más que la representatividad estadística se buscaron ejemplos de prácticas de enseñanza con videojuegos. Para la recolección de los datos se utilizaron encuestas, entrevistas, observación y análisis de los juegos empleados. Los dos primeros fueron los instrumentos más importantes de esta investigación.

Como resultado se descubrieron distintos escenarios: construcción de conocimientos, aplicación, evaluación, integración social y de recreación, con los propósitos de motivar, facilitar el aprendizaje, aplicar conocimientos, evaluar y recrear, los que serán desarrollados en este artículo.

PALABRAS CLAVE: videojuegos, enseñanza, propósitos, Plan CEIBAL, tecnologías 


\section{Abstract}

Video games are part of recreational activities of children in today's society. They can spend hours playing video games and concentrate on them intensely. Several authors have wondered why not to use video games in education. The Primary Education curriculum notes that games should be developed intentionally by teachers both as a content in itself and as a methodological strategy.

At the Plan CEIBAL's assessment, children say that what interest them the most of the XO laptops are the games. The research conducted in 2012 at six full-time schools aimed at analyzing the use of video games by teachers in the classroom.

Information was collected in order to know whether, in these particular schools, there was a link between recreational activities and teaching. In those particular cases the purpose was to get to know what teachers aimed at when planning activities which included videogames and in what scenarios they were carried out.

The design of this research was exploratory and descriptive. A mixed methodology was used through a purposive sample composed of six full-time schools in Montevideo of different social environments. Examples of teaching practices with video games were sought rather than statistical representativeness. Data collection was carried out through surveys, interviews, observation and analysis of the games used in the class. Surveys and interviews were the most important tools for this research.

As a result different learning areas could be related to the use of videogames such as knowledge construction, implementation, evaluation, social integration and recreation, with the purposes of: motivating children, facilitating learning processes, applying knowledge, evaluating and recreating, which will be developed in this article.

KEYWORDS: video games, teaching purposes, Plan CEIBAL, technologies

\section{Introducción}

El presente trabajo es fruto de la investigación titulada "¿A qué jugamos hoy? Los videojuegos en XO en seis Escuelas de Tiempo Completo: de lo sociocultural a lo didáctico pedagógico" (Geymonat, 2013), que realizáramos en los años 2011-2012 y que se enmarcó dentro de la línea de las tecnologías educativas, dicha investigación vinculada con el Plan Ceibal' ${ }^{1}$.

La idea de investigar sobre esta temática surgió de la lectura de los resultados de la evaluación del Plan CEIBAL efectuada en el año 2010, donde se constatan las preferencias de los niños por Internet y, en especial, por los juegos digitales, ya sea tanto los que "descargan" en las computadoras portátiles (XO) como los juegos en línea.

Como propósito nos planteamos "indagar si los docentes emplean los videojuegos en sus clases, y si lo hacen, cómo, cuándo y qué intencionalidad tienen” (Geymonat, 2013, 14).

\section{Antecedentes}

En la búsqueda de tesis académicas nacionales e internacionales no se hallaron, a nivel nacional, investigaciones que relacionaran "videojuegos" con prácticas de enseñanza. Sin embargo, se constató que los videojuegos son considerados instrumentos para la enseñanza tanto en el Portal CEIBAL como en el Portal Uruguay Educa, ambos portales educativos oficiales de Uruguay.

Por el contrario, en el ámbito internacional fueron abundantes los hallazgos de tesis de Maestría y de Doctorado que coinciden en indicar el potencial educativo que poseen los videojuegos, y que señalan que la utilización de algunos de ellos puede estimular el desarrollo de 
habilidades y competencias. Todos estos hallazgos resaltan el valor que tienen los videojuegos para motivar el aprendizaje de contenidos de diferentes áreas del conocimiento y el tratamiento de temas tales como familia, valores, drogadicción, respeto a las reglas, etc.

\section{Revisión bibliográfica}

Al realizar la revisión bibliográfica los autores que sobresalen a nivel internacional son Bartolomé (1999), Prensky (2001), Wolf (2005), Gros (2008), Litwin (2009), Piscitelli (2009), Jackson y Montero (2010) y Lacasa (2011) entre otros.

Para Pilar Lacasa (2011), con los videojuegos la persona puede pensar de forma "apasionada". Por ese motivo, plantea la posibilidad de utilizarlos en el plano educativo. Según Gros (2008), estos juegos pueden proporcionar al alumno un importante instrumental de autoaprendizaje que lo prepararía para afrontar otras situaciones de aprendizaje. Según Molinas (en Litwin, 2009), llevan al alumno a reflexionar sobre las acciones y las decisiones, a autoevaluar las estrategias utilizadas, a comparar distintas formas de solucionar los problemas, a adoptar una actitud crítica sobre los contenidos y a tomar decisiones respecto de incluir otros conocimientos necesarios para poder continuar el juego.

Los videojuegos, que pertenecen a la cultura actual, combinan diversas formas de representación: imágenes, audio y movimiento y pueden ser muy útiles a la hora de enseñar contenidos de distintas áreas del conocimiento. Por su parte, Bartolomé (1999) encuentra semejanza en el diseño de los videojuegos con el de las simulaciones.

\section{Principales conceptos que dieron sustento a la investigación}

\section{¿Qué se entiende por videojuego?}

El término "videojuego" comenzó a utilizarse en la década del 70. Según Pere Marquès Graells un videojuego es: "todo tipo de juego digital interactivo, con independencia de su soporte (ROM interno, cartucho, disco magnético u óptico, on-line) y plataforma tecnológica (máquina de bolsillo, videoconsola conectable al TV, teléfono móvil, máquina recreativa, microordenador, ordenador de mano, video interactivo)" (Marquès, 2001). En todos es importante la acción del jugador e integran diversas notaciones simbólicas (textos, sonidos, fotografías, videos, música, imágenes en tres dimensiones); son dinámicos y altamente interactivos.

Wolf y Perron dicen al respecto: "Actualmente el videojuego es considerado todo tipo de cosas, desde ergódico (de trabajo) hasta lúdico. Se lo considera narración, simulación, performance, re-mediación (paso de un medio a otro) y arte; una herramienta potencial para la educación o un objeto de estudio para la psicología del comportamiento; un medio para la interacción social, y -no hace falta decirlo- un juguete y un medio de distracción. Asimismo, el campo emergente de la teoría del videojuego también constituye el punto de convergencia de una gran variedad de enfoques, que incluyen la teoría del cine y la televisión, la semiótica, la teoría de la performance, los estudios del juego, la teoría literaria, la informática, las teorías del hipertexto, el cibertexto, la interactividad y la identidad, el posmodernismo, la ludología, la teoría de los medios de comunicación, la narratología, la estética y la teoría del arte, la psicología, las teorías de los simulacros, entre otros. El hecho es que el estudio de los videojuegos se ha convertido en un punto de convergencia del pensamiento teórico contemporáneo" (Wolf y Perron, 2005, 2). 
Por su parte, para Egenfeldt-Nielsen (2005), un videojuego es un juego diseñado y creado para ser jugado en una computadora, que contiene un conflicto artificial con su posterior equilibrio y resolución. Esto último posibilita a los jugadores aprender al proponerse un objetivo y lograr alcanzarlo. En muchos de estos juegos se realiza un simulacro de situaciones tomadas de la vida real.

En esta investigación se consideró "videojuego" a todo juego que se pueda descargar en la XO o a los que se juegan en Internet en las computadoras entregadas por el Plan CEIBAL a los alumnos de escuelas públicas (XO), diseñados o no con una intencionalidad didáctica.

\section{Características del juego}

Pilar Lacasa (2011) indica estas características del juego en general:

- No es considerado una actividad seria, pues se efectúa fuera de la vida ordinaria.

- En general es absorbente, por lo que el jugador llega a olvidarse de su entorno inmediato.

- Se trata de una actividad que está más vinculada con la emoción que con el conocimiento.

- No se encuentra asociado a intereses materiales.

- En todo juego existen reglas, que son fijas y que el jugador debe conocer y actuar en concordancia con ellas.

- Se trata de una actividad que se realiza en un tiempo y espacio con ciertos límites.

- Posibilitan la creación de grupos sociales que se transforman en verdaderas comunidades.

\section{Valor pedagógico del juego}

El juego también posee un gran valor pedagógico. Los niños, a través del juego, desarrollan su pensamiento, su imaginación, su creatividad, a la vez que construyen formas de responder a las preguntas que se les presentan y, de esta manera, también obtienen dominio y equilibrio emocional, desarrollan la sociabilidad al comunicarse y cooperar con otros.

Según Vigotsky (1988) el juego es una actividad que permite al niño ensayar respuestas a diversas situaciones complejas y actuar por encima de su edad promedio sin temor al fracaso, a diferencia de lo que sucede en la vida real. El juego es un factor decisivo en el desarrollo.

Desde el punto de vista psicológico presenta las siguientes características: motivación intrínseca, simbolización y relación medios-fines. Estas características son importantes también desde el punto de vista pedagógico.

Otro aspecto significativo de los juegos son sus reglas preestablecidas, las que deben ser conocidas de antemano o descubiertas en el desarrollo del juego, y que al ser respetadas permiten la incorporación de valores.

\section{Valor pedagógico de los videojuegos}

Los conceptos mencionados respecto a las actividades lúdicas en general se pueden aplicar también a los juegos digitales. Pero, por su característica distintiva de juego digital se agregan otros valores propios. Autores como Lacasa, Prensky, Gros y Nielsen destacan el valor pedagógico de los videojuegos.

Con los videojuegos las personas son capaces de aprender, opina Nielsen (2005). Primero, el jugador aprende las reglas y el funcionamiento. Luego aprende sobre el contenido de los mismos. Nielsen defiende el uso de los videojuegos "comerciales" en la educación pues, por lo general, estos juegos requieren mayor actividad del jugador que los creados con una finalidad meramente educativa. 
El Grupo de Investigación F9 (2006) estima que cuando los videojuegos son empleados en la enseñanza con objetivos previamente definidos, favorecen el desarrollo de distintos niveles de competencias tales como:

- Competencias instrumentales: al adquirir dominio sobre el uso de software y del hardware, al descargar e instalar juegos, guardarlos, recuperarlos y utilizarlos.

- Competencias para la gestión de recursos por medio del empleo de distintos tipos de lenguajes y el desarrollo de habilidades para la búsqueda, selección, procesamiento, comunicación y registro de la información.

- Competencias en entornos multimedia: navegación, feedback, nivel de comunicación, intencionalidad.

- Competencias para la comunicación oral y escrita con incorporación de vocabulario propio de los juegos, a través del uso de blogs, foros, chats, correos electrónicos.

- Competencias para la crítica, pues permiten desarrollar la actitud crítica y reflexiva sobre su funcionamiento, los temas que tratan, los elementos que los componen, conductas, valores y contravalores que se aprecian en los mismos.

A continuación, el cuadro realizado por Tere Vida y Teresa Hernández (2008) muestra una síntesis del valor educativo de los videojuegos.

\section{Cuadro $\mathrm{N}^{\circ}$ 1. Valor educativo de los videojuegos}

\section{FUNCIONES}

Actualmente existe tal variedad de tipos de videojuegos que no podemos generalizar y decir que todos favorecen el desarrollo de estas funciones. Según la tipología de juego y su calidad de diseño potenciarán unas u otras:

\section{Personales /emocionales}

- Motivan;

- Proporcionan placer y satisfacción;

- Estimulan la superación personal y la capacidad para enfrentarse a retos;

- Promocionan la autoconfianza;

- Son una oportunidad para la expresión de sentimientos.

\section{Sociales}

- Favorecen la interiorización de normas y pautas de comportamiento social;

- Facilitan la aproximación y comprensión de la tecnología y el lenguaje audiovisual;

- Posibilitan la comunicación directa e indirecta;

- Fomentan la cooperación, la colaboración y el trabajo en equipo.

\section{Psicomotrices}

- Desarrollan la coordinación viso-manual;

- Estimulan la orientación espacial;

- Potencian habilidades motrices como la rapidez, la puntería, la precisión;

- Promueven la coordinación de movimientos, en el caso de la nueva línea de videojuegos motores en los que la interacción del usuario con el programa implica un movimiento corporal.

\section{Cognitivas}

- Estimulan la curiosidad, motor de todo aprendizaje;

- Potencian la percepción visual y auditiva;

- Favorecen la adquisición de habilidades organizativas, analíticas, de exploración y observación, creativas;

- Potencian la adquisición de estrategias para la toma de decisiones y la resolución de problemas;

- Desarrollan aprendizajes significativos transferibles;

- Fomentan el análisis y contraste de valores y actitudes.

De esta forma, en el cuadro de Vida y Hernández (2008: 96) se destaca el valor educativo que pueden brindar muchos videojuegos. Pero, asimismo, se hace puntualización: no todos poseen igual valor educativo. 


\section{De lo sociocultural a lo didáctico-pedagógico}

El hecho de la incorporación de los videojuegos a la vida de niños, adolescentes y jóvenes es un acontecimiento sociocultural que comenzó a fines del siglo XX y que continúa en el presente siglo. En Uruguay, los alumnos que asisten a las escuelas o a los liceos públicos cuentan con las computadoras que les fueron entregadas por el Plan CEIBAL. Al ser de su propiedad, las llevan a sus hogares y las utilizan tanto para contenidos educativos como para entretenimiento.

Según Prensky (2001), los estudiantes actuales, a los que denomina "nativos digitales" pertenecen a la generación digital y presentan características propias: capacidad de procesar en paralelo (atender a distintas partes de la pantalla con temas diferentes), capacidad de comprender relatos no lineales (hipertextuales) y atracción por las imágenes. Considera que los estudiantes actuales desarrollan mentes hipertextuales y que los procesos de enseñanza puramente lineales pueden retrasar el desarrollo de esas mentes.

Otra característica de los nativos digitales según Prensky, es la interactividad y la gran capacidad de concentración en los asuntos que les interesa como, por ejemplo, los videojuegos, pero tienen dificultades para concentrarse en las formas tradicionales de enseñanza.

Hasta hace poco tiempo se consideraba que los videojuegos eran un mero entretenimiento, una pérdida de tiempo, y de modo alguno un recurso que se pudiera emplear en la enseñanza formal. Sin embargo, estos nuevos artefactos culturales pueden considerarse como mediatizadores de los aprendizajes de niños y adolescentes. Según Wolf (2005) los videojuegos han dejado de ser algo marginal para convertirse en un elemento clave dentro de las tecnologías.

En el título de la investigación se encuentra la expresión "De lo sociocultural a lo didácticopedagógico", con la que se pretendió hacer alusión al hecho de que los videojuegos pueden ser utilizados como recursos didáctico-pedagógicos. En nuestro país se han desarrollado actividades y juegos, por un lado para ser utilizados en las computadoras del Plan CEIBAL y que han sido diseñados especialmente para ser empleados en la enseñanza y el aprendizaje, y por otro lado videojuegos de simple entretenimiento que se utilizan fuera de la escuela. En el Portal del mencionado Plan, tanto niños como adolescentes encuentran información sobre los nuevos juegos disponibles.

\section{La investigación}

\section{Objetivos de la investigación}

De acuerdo con lo expresado en la introducción y a los antecedentes encontrados, en esta investigación se buscó la concreción de los siguientes objetivos:

\section{Objetivo general}

"Identificar los propósitos y escenarios en que los docentes de escuelas públicas de Tiempo Completo de Montevideo utilizan los videojuegos en sus clases"(Geymonat, 2013, 15).

\section{Objetivos específicos}

- Relevar y analizar los escenarios didácticos en que los docentes aplican juegos digitales en los procesos de enseñanza y aprendizaje.

- Identificar los propósitos de los docentes al utilizar los videojuegos.

- "Indagar qué habilidades, conocimientos y competencias pretenden lograr los docentes con el empleo de juegos digitales" (Geymonat, 2013, 15). 


\section{Diseño metodológico}

El diseño de la investigación fue exploratorio y descriptivo. Se buscó la familiarización con el problema, descripción y explicación de los hallazgos. La metodología empleada fue mixta: cuantitativa y cualitativa por medio de una muestra intencional que estuvo compuesta por seis escuelas de Tiempo Completo ${ }^{2}$ de Montevideo, de diferentes contextos socioeconómicos y culturales. Más que la representatividad estadística se pretendió encontrar prácticas de enseñanza que involucraran el uso de videojuegos.

Los motivos para seleccionar escuelas de este tipo fueron los siguientes:

- Los alumnos, desde los 4 años, son atendidos en el horario de 8:30 a 16 horas según la Resolución Nº 21 del Acta 90 del año 1998 del Consejo Directivo Central (CO.DI.CEN.) de la Administración Nacional de Educación Pública (A.N.E.P.) $)^{3}$.

- Una investigación anterior (Curbelo, 2010) mostró que el empleo de videojuegos en la enseñanza requiere mayor disponibilidad de tiempo, tanto en la planificación como en la clase misma.

- Los docentes desarrollan su labor en 40 horas semanales, las que incluyen dos horas y media de intercambio y coordinación, lo que les proporciona mayor posibilidad para compartir "buenas prácticas".

- Asimismo, los alumnos tienen instancias formativas como "La hora de juego"

- Un horario más amplio, así como espacio de coordinación y presencia de profesores especiales facilitarían la realización del trabajo de campo sin interferir con la labor docente.

De acuerdo con los datos del Monitor Educativo ${ }^{4}$ del año 2010, tres de las escuelas de la muestra pertenecen a contextos de Quintil 5, que son las menos vulnerables, una de Quintil 1, muy vulnerable, una de Quintil 2 y otra de Quintil 3 ("Medio"), tal como se puede ver en el siguiente cuadro. (Las escuelas aparecen designadas con números romanos del I al VI, para mantener el anonimato).

Cuadro $N^{\circ} 2$ Contexto de las escuelas según el Monitor Educativo de Primaria, año 2010

\begin{tabular}{|c|c|}
\hline Escuela & $\begin{array}{c}\text { Contexto } \\
\text { Sociocultural }\end{array}$ \\
\hline I & Nivel o quintil 5 \\
\hline II & Nivel o quintil 5 \\
\hline III & Nivel o quintil 3 \\
\hline IV & Nivel o quintil 5 \\
\hline V & Nivel o quintil 1 \\
\hline VI & Nivel o quintil 2 \\
\hline
\end{tabular}

La muestra de escuela tenía un total de ochenta y ocho docentes (entre maestros de aula y profesores de Educación Física e Inglés), sin contar los equipos de Dirección pues no fueron encuestados ni entrevistados.

\section{Recolección de los datos}

Se entregaron encuestas a todos los docentes de la muestra y se recogieron sesenta y dos encuestas respondidas. Se realizaron diez entrevistas, así como observación y análisis de los juegos empleados. 
Las encuestas estaban compuestas por preguntas abiertas y preguntas cerradas, con un total de veintitrés. Según el contenido pueden clasificarse en dos grupos diferentes: el primero, con ocho preguntas, indagaba aspectos del docente y de la clase a su cargo con ítems referentes a sexo, edad, años de docencia, años en escuelas de tiempo completo, grado escolar a su cargo y número de alumnos en el grado. En el segundo grupo, con quince preguntas, el tema es la utilización de las XO con sus alumnos. De esas preguntas, once están dirigidas a obtener información específica sobre la utilización de videojuegos en sus prácticas escolares. (EI instrumento utilizado se encuentra en la sección ANEXOS).

Con las entrevistas semiestructuradas se pretendió profundizar en aspectos relativos a la utilización de los videojuegos en el aula. Para la elección de los docentes a entrevistar se obtuvo información de docentes calificados (Maestros directores) o por medio de la técnica de "bola de nieve". Tal fue el caso de una maestra que dijo: "También podrías entrevistar a mi paralela, porque ella usa juegos en las XO en sus clases" (M1, Escuela I). Aquí un docente señala a otro docente, al que también se le realiza una entrevista.

La hora y el lugar de la entrevista fueron acordados previamente. Las entrevistas se realizaron en lugares como la sala de informática, la secretaría o el salón de clase pero siempre sin la presencia de alumnos o de interferencias pues se buscó el momento en que los alumnos estuvieran atendidos por profesores especiales o en el recreo.

Las entrevistas tuvieron una duración de entre diez y veinte minutos y la misma dependió de si el maestro se explayaba más en el tema o no. (Las preguntas guía de la entrevista se encuentran en la sección ANEXOS).

Otra estrategia metodológica empleada fue la observación de los juegos nombrados en las entrevistas, lo que llevó a la confección de una lista de los juegos citados, con descripciones e imágenes.

Cuadro $\mathrm{N}^{\circ}$ 3. Síntesis del trabajo de campo

\begin{tabular}{|c|c|c|l|}
\hline Escuelas & Encuestas & Entrevistas & \multicolumn{1}{|c|}{ Observaciones } \\
\hline I & 17 & 3 & $\begin{array}{l}\text { Junio. Se inicia el trabajo de } \\
\text { campo con encuestas y tres } \\
\text { entrevistas a dos maestras y una } \\
\text { profesora de inglés. }\end{array}$ \\
\hline II & 13 & 2 & $\begin{array}{l}\text { Octubre. Encuestas y dos } \\
\text { entrevistas a maestras. }\end{array}$ \\
\hline III & 5 & 2 & $\begin{array}{l}\text { Setiem b re. En total siete } \\
\text { maestras encuestadas. } \\
\text { Entrevistas a dos maestras. }\end{array}$ \\
\hline IV & 3 & 1 & $\begin{array}{l}\text { Agosto. Faltaban dos maestras } \\
\text { yo todas devolvieron Ias } \\
\text { encuestas. } \\
\text { Noviembre. Entrevista a maestra } \\
\text { de clase. }\end{array}$ \\
\hline V & 11 & 1 & $\begin{array}{l}\text { Julio. Encuestas y una entrevista } \\
\text { a profesora de Educación Física. }\end{array}$ \\
\hline VI & 13 & 1 & $\begin{array}{l}\text { Julio. Encuestas y una entrevista } \\
\text { a maestra de clase. }\end{array}$ \\
\hline Totales & 62 & 10 & \\
\hline
\end{tabular}




\section{Procesamiento de los datos}

Para trabajar con los datos obtenidos, debieron transcribirse las entrevistas grabadas y organizar y codificar la información. Para realizar el análisis estadístico-descriptivo se utilizó el software Statistical Package for the Social Sciences o SPSS (Paquete Estadístico para las Ciencias Sociales).

Las respuestas obtenidas con la aplicación de los cuestionarios fueron analizadas, en lo referente al porcentaje, respecto de la muestra completa de sesenta y dos entrevistas. Luego se construyeron distintas tipologías. De acuerdo con Flick, "la distribución de las respuestas del cuestionario y la tipología se usan y comparan” (Flick, 2007, 281).

La triangulación de la información se realizó por medio de la combinación de instrumentos cuantitativos y cualitativos, es decir, a través de los datos obtenidos en encuestas, entrevistas y análisis de los videojuegos citados. Los resultados "convergen y se confirman mutuamente y apoyan las mismas conclusiones" (Flick, 2007, 283).

\section{Resultados}

\section{Consideraciones generales}

En los hallazgos, cualitativos y cuantitativos, los más destacados son los propósitos y los escenarios en que los docentes realizan estas actividades. Es notoria la información recogida en relación a las edades de los docentes que más utilizan las XO y a los videojuegos que más emplean pues dicha información no concuerda con la opinión general de las personas. A través de las encuestas de esta muestra quedó en evidencia que los docentes más jóvenes (21 a 30 años) son los que menos emplean las XO en sus clases y, sin embargo, la mayor utilización corresponde a los docentes con más de 40 años de edad y más de 20 años de trabajo.

El 94\% de los docentes encuestados en la muestra reconoce que los videojuegos permiten desarrollar habilidades y competencias importantes tanto para el trabajo escolar como para su desarrollo integral como persona. Las habilidades y competencias que más destacan son: agilidad mental, creatividad, rapidez de respuesta, capacidad de orientación y para leer mapas, búsqueda de información, capacidades organizativas, capacidad de comprensión, atención, razonamiento, memoria, trabajo colaborativo y perseverancia.

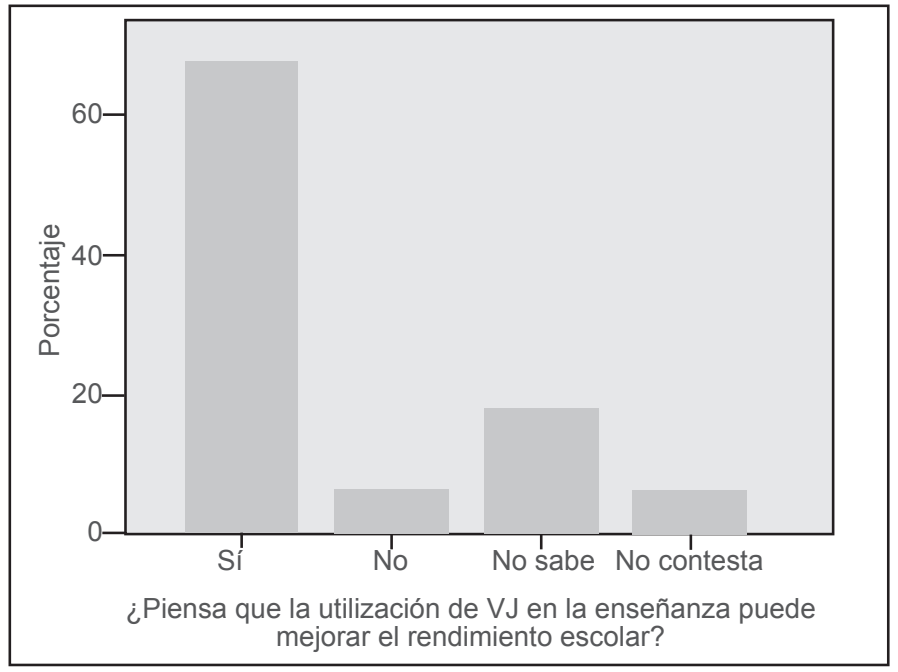


Además, para el $68 \%$ de los docentes de esta muestra, los juegos digitales podrían producir una mejora en el rendimiento escolar. Para argumentar esto expresaron lo siguiente:

"A través de lo lúdico se llega a motivar a muchos niños que presentan dificultades de participación espontánea". (Encuesta 26 - M8 - Escuela V)

"Sirve ampliamente de apoyo visual y permite mayor involucramiento..." (Encuesta 1 - M1 Escuela II)

"Aprenden jugando, afirman conocimientos, uso adecuado de juegos en horario escolar". (Encuesta 2 - M2 - Escuela II)

"Con un propósito bien definido, al igual que el contenido a trabajar en el grado". (Encuesta 15 - M2 - Escuela III)

"Complementa el aprendizaje de contenidos". (Encuesta 17 - M4 - Escuela III)

"Desarrolla estrategias de leer, organizarse y resolver situaciones (estrategias de resolución)." (Encuesta 38 - M9 -Escuela VI)

"Desarrolla la creatividad y los estimula". (Encuesta 53 - M8 - Escuela I)

"Favorece la toma de decisiones, la autonomía, el juicio crítico; eleva la autoestima". (Encuesta 37 - M8 - Escuela VI)

"La posibilidad de trabajar con el contenido desde otra mirada". (Encuesta 11 - M11 - Escuela II) "Lo que se aprende jugando se aprende más rápido y se recuerda más". (Encuesta 6 - M6 Escuela II)

"Representan una forma distinta de alcanzar diferentes conocimientos y promover distintos aprendizajes". (Encuesta 29 - M5 - Escuela V)

"La inclusión de nuevas tecnologías y contenidos en este nivel (inicial 5) se realiza en gran medida a través de las actividades lúdicas". (Encuesta 35 - M6 - Escuela VI)

"Es una herramienta que estimula a los niños; pasos previos para el desarrollo de los contenidos". (Encuesta 44 - M2 - Escuela IV)

"El rendimiento escolar mejora con dispositivos y estrategias didácticas potentes. El videojuego es solo un recurso. Si no se usa encuadrado en una potente planificación de contenidos bien secuenciados, por sí mismo no mejora los rendimientos". (Encuesta 43 - M1 - Escuela IV)

"Sin duda que bien empleados pueden significar instancias de aprendizaje, recreación, mejoramiento de la convivencia”. (Encuesta 45 - M3 - Escuela IV)

"Adquieren conocimientos sin tener que escribir; se focaliza la atención y se aprende en forma atrayente e interesante". (Encuesta 46 - M1 - Escuela I)

La motivación es uno de los aspectos más resaltados por los docentes:

"El alumno aprende jugando y motivado, para continuar aplicando lo que aprende en otras áreas". (Encuesta 62 - M17 - Escuela I)

"Los entusiasma, favorece la adquisición de destrezas, percepción, concentración, etc." (Encuesta 18 - M5 - Escuela III)

“...para motivar los aprendizajes. Aprenden más a través del juego.” (Encuesta 7 - M7 - Escuela II)

"Porque el aspecto lúdico es el que más motiva al niño. Debido a que es lo que les interesa, los 'atrapa', les llama la atención”. (Encuesta 19 - M1 - Escuela IV)

"Evidentemente, el juego los motiva a aprender ese contenido de una manera más divertida, más alegre, y, de este modo, la organización de la clase es buena... no hay problemas de disciplina... están todos motivados..." (Entrevista 10 - M1- Escuela IV)

"Es de gran motivación y creación". (Encuesta 49 - M4 - Escuela I) 
Sin embargo, a pesar de los argumentos anteriores, se constató que solamente el $34 \%$ de los docentes que completaron las encuestas manifiestan que utilizan "muchas veces" los videojuegos en sus clases. Y más llamativo aún es el hecho de que solo el $11 \%$ los menciona en sus planificaciones.

Por otra parte, también encontramos un porcentaje importante (32\%) que no argumenta a favor de que la utilización de los videojuegos pueda mejorar el rendimiento escolar. Al respecto, se encontraron diversas posiciones: por un lado, aquellos que categóricamente afirman que dicha utilización no produce mejoría alguna; otros manifiestan dudas al respecto y otros consideran que esa imposibilidad de mejorar el rendimiento se debió más bien a la falta de formación adecuada para usarlos con un propósito pedagógico.

De esta investigación se desprende que la aceptación y valoración por parte de los docentes es amplia pero no se refleja en los porcentajes que admiten su utilización frecuente. Por lo tanto nos planteamos una nueva interrogante: ¿Por qué, si el $94 \%$ de los encuestados opina que los videojuegos incorporan aspectos positivos y el $60 \%$ considera que, efectivamente, producen una mejora en el rendimiento, solo el 34\% lo emplea en el aula? En el Apartado 5.5 "Fortalezas y debilidades", se realizan varias reflexiones con la intención de dar explicaciones a la pregunta anterior.

\section{Propósitos}

Un objetivo importante de esta investigación fue conocer los propósitos con que los docentes de esta investigación utilizan los videojuegos en el aula. Dichos propósitos son los siguientes:

Motivar. Es el que más se ha destacado. La mayoría de los docentes coincide en expresar que el juego motiva el aprendizaje de contenidos de una manera más motivadora que cuando lo hacen con recursos tradicionales. Esa motivación logra que los alumnos se muestren más interesados y que no se produzcan problemas de disciplina. Algunos docentes entrevistados manifestaron que los juegos deben poseer un grado de dificultad adecuado que represente un desafío que entusiasme a los niños a continuar jugando. Por lo tanto, no deben ser ni excesivamente difíciles ni muy fáciles. Al respecto, la Maestra 3 de Escuela III dice en la encuesta: "Los niños se encuentran sumamente motivados, les prestan más atención". A su vez, la Maestra 7 de la Escuela II en la Encuesta 7 nos dice: "Sirve para motivar los aprendizajes. Aprenden más a través del juego".

Facilitar el aprendizaje. Los videojuegos pueden proporcionar determinado andamiaje debido al hecho de que cumplen cuatro funciones esenciales: brindan apoyo, sirven de herramienta, amplían el alcance del sujeto y pueden usarse selectivamente. Los docentes consideran que "...lo que se aprende jugando se aprende con más facilidad, se recuerda más..." (Maestra 2 Escuela II). En la entrevista 6, la Maestra 1 de la Escuela III expresa: “...vienen con inquietudes, con preguntas... a través de un juego lo pueden entender mejor.” 


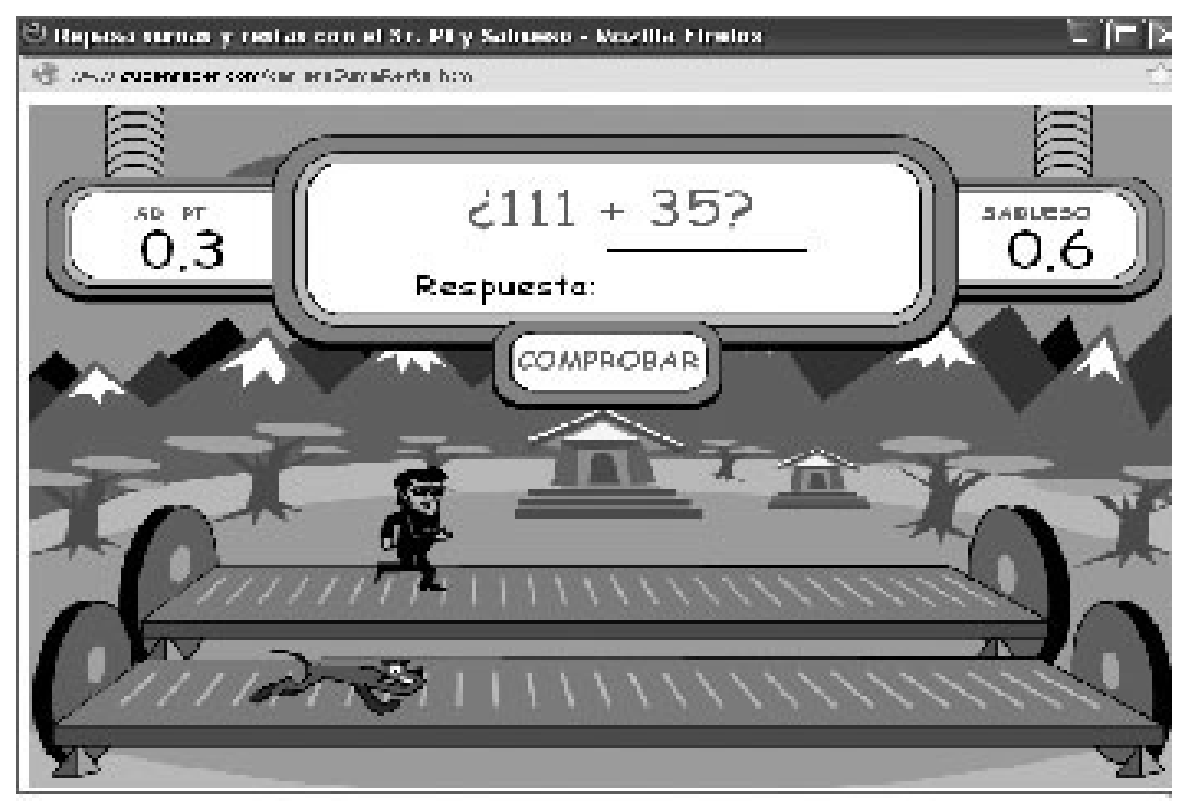

Aplicar conocimientos. El 16\% de los docentes que completaron las encuestas manifestó que un propósito para emplear determinados videojuegos es que los alumnos apliquen conocimientos acerca de contenidos programáticos previamente trabajados. En tal sentido mencionaron algunas propuestas en los videojuegos como laberintos, juegos de asociación, de reconocimiento de letras, formas, números, sonidos, entre otros. Los propósitos manifestados por los docentes fueron: "Afirmar y confirmar conocimientos" (Encuesta 48 - M1 - Escuela I), "Ejercitación de contenidos" (Encuesta 49 - M2 - Escuela I), "Ejercitar o reforzar lo aprendido. Brindar una mirada diferente a lo aprendido" (Encuesta 6 - M6 - Escuela II).

Recrear. Uno de los propósitos más señalados fue el exclusivamente lúdico y recreativo, que se da en los escenarios que fueron denominados por los docentes como "hora del juego" y "descanso con XO".

Evaluar. Es otro de los propósitos mencionados por algunos docentes. Manifestaron que la evaluación se realiza por medio de la observación de la actividad individual de los niños durante el juego y/o del trabajo colaborativo en los mismos.

Atender a la diversidad. Señalado como propósito por los docentes, quienes coinciden con Greenfield (1985) en que la utilización de los videojuegos con niños que presentan dificultades de aprendizaje puede ser beneficiosa tanto en el tratamiento de contenidos como de algunas habilidades básicas, tanto por el importante papel en la motivación como por la retroalimentación inmediata, pues proporcionan un estímulo a la curiosidad de los niños.

\section{Escenarios}

Otro aspecto de la investigación fue la construcción de los distintos escenarios educativos en que los docentes emplean los juegos en sus prácticas de enseñanza, a los que denominamos "de construcción de conocimientos", "de aplicación de conocimientos", "de evaluación”, "de integración social” y "de recreación". 


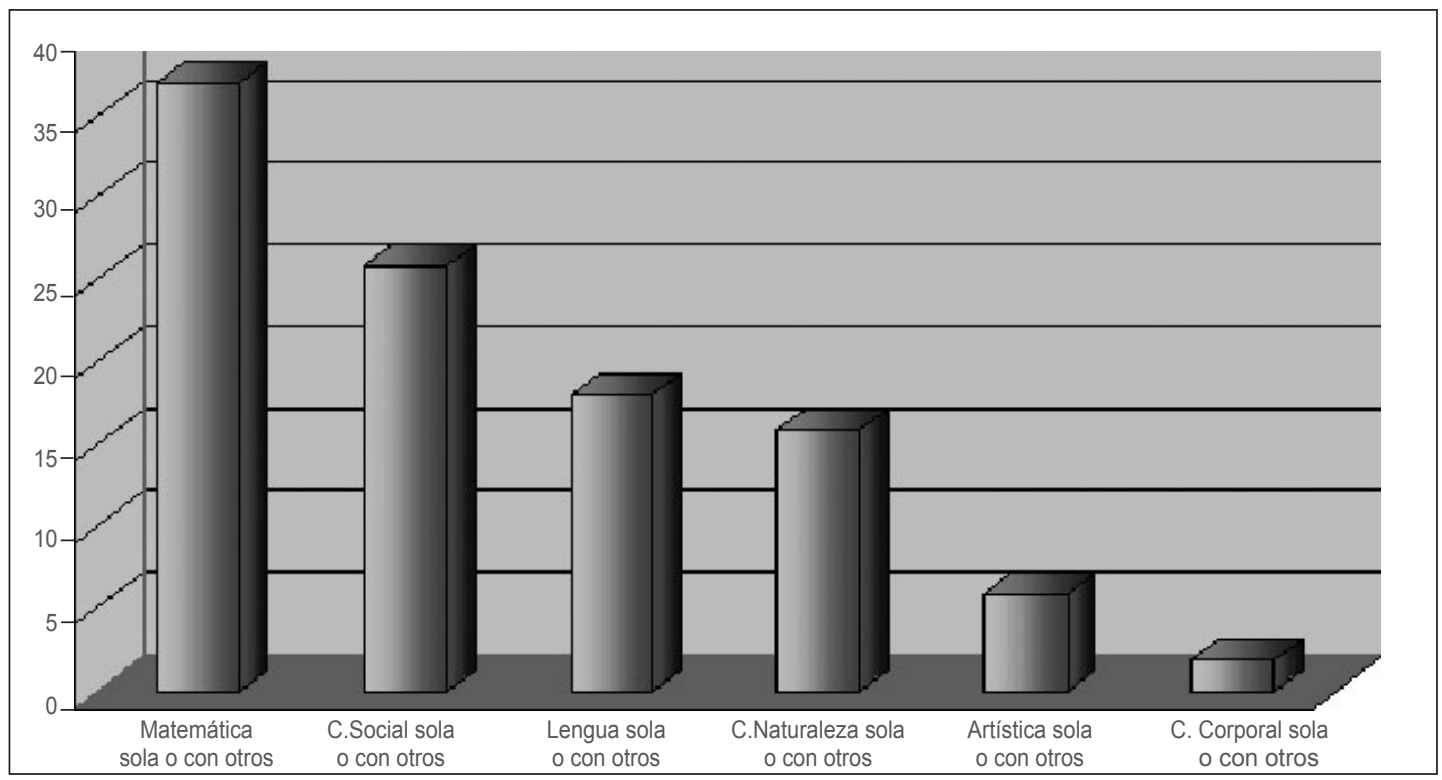

Escenario de construcción de conocimientos. En general, en este escenario los videojuegos son empleados dentro de proyectos de aula o en secuencias de enseñanza. El juego se presenta tanto al comienzo de la secuencia para introducir un contenido, como en el medio o al final de la misma.

Un hallazgo de esta investigación fue la constatación de que la mayoría de los docentes manifiesta que los utiliza en el Área de Matemática en primer lugar (37\%). Menor es el porcentaje de quienes los emplean para abordar contenidos de otras áreas del conocimiento: Ciencias Sociales (26\%), Área del Conocimiento de Lengua (18\%), de la Naturaleza (16\%), del Conocimiento Artístico (5\%) y del Conocimiento Corporal (2\%).

Varios de los juegos utilizados conducen al niño a la indagación, a la búsqueda de información. Así se apropian tanto de los conocimientos generales de la cultura como de los específicos del contenido que se trata.

Simultáneamente a la adquisición de conocimientos se produce el desarrollo de competencias que permiten la construcción de representaciones mentales. Se favorece así el desarrollo de la capacidad lectora, la conciencia ortográfica, el pensamiento lógico, la observación, la espacialidad, la ampliación del vocabulario, la capacidad de resolver problemas y planificación de estrategias, y la necesidad de buscar información, entre otras.

Escenario de aplicación de conocimientos. Dentro de las secuencias de enseñanza, los docentes emplean algunos juegos para que sus alumnos apliquen los conocimientos que construyeron durante los mismos y/o algunos conocimientos previos. Son juegos donde los alumnos completan oraciones o palabras, escriben el resultado de una operación, realizan selecciones múltiples, responden "verdadero o falso" y realizan asociaciones de palabras o de ideas. Muchos se parecen más a ejercitaciones realizadas en soporte digital que a videojuegos. Pero por el hecho de recurrir a las computadoras, la mayoría de los niños los asocian con los "juegos" y se sienten más motivados. 
Escenario de Evaluación. Existen videojuegos que los docentes emplean para evaluar si se ha logrado la construcción de determinados conocimientos por parte de sus alumnos. Algunos presentan la opción de intentarlo otras veces, lo que hace posible que el propio alumno pueda corregir errores y aprender con la retroalimentación. En otros, la respuesta automática que reciben los niños está de acuerdo a sus intereses, pues prefieren que la devolución sea inmediata. La intervención del docente, con retroalimentaciones, así como las propias reflexiones de los alumnos son aspectos muy valiosos. Los docentes determinan en qué momento deben intervenir para promover el avance cognitivo. Se trata de una evaluación formativa, que permite al alumno aprender.

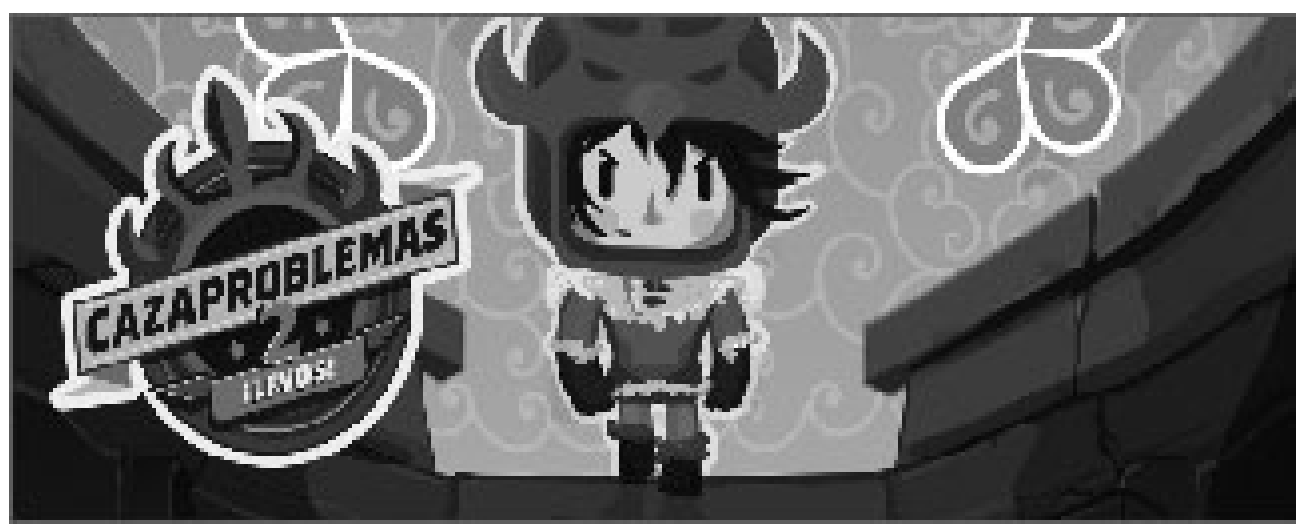

También se pueden encontrar videojuegos que plantean problemas o eventos simulados, que son muy útiles para desarrollar en los niños la capacidad de tomar decisiones. Más importante aún que llegar a la solución del problema son los procedimientos que deben realizar para poder encontrar esa solución, tales como el trabajo colaborativo entre los alumnos donde se realiza un intercambio de opiniones, donde preguntan, buscan información, seleccionan, se consultan entre ellos y consultan al docente. De esta manera se promueven las habilidades interpersonales a través de la aceptación de reglas, la cooperación y la toma de decisiones.

Escenario de Recreación. Es el que se desarrolla en la "hora del juego", en "el descanso" que se realiza después del almuerzo o en los minutos finales de la jornada de trabajo en la clase (por lo general, veinte minutos). Referente a este escenario, algunas docentes entrevistadas manifiestan que intervienen para evitar el uso de juegos violentos e incentivan a que los niños empleen los mismos juegos que se utilizaron para la enseñanza de un contenido, para la aplicación o para la evaluación.

Los docentes explicaron tres formas distintas al emplear estas actividades lúdicas en la "hora del juego" o en la "hora de descanso": en forma libre, semilibre y no libre (o vigilada). Hay diferentes formas de proceder: por un lado, están los docentes que permiten que sus alumnos seleccionen libremente los juegos para este espacio que denominan, en general, "juego libre con XO"; por otro lado, los que ponen como condición que los juegos que seleccionen no posean contenidos violentos o inadecuados, y, finalmente, los que en esta hora recomiendan que los niños utilicen los mismos juegos que emplearon cuando se trataron determinados contenidos programáticos. 
Escenario de integración social. Si bien se utilizan en las computadoras del "Modelo 1 a 1" (una computadora, un niño), los videojuegos también pueden favorecer la integración social tanto cuando se realizan juegos en equipos como cuando comparten una XO (porque no todos los alumnos tienen la suya en clase), cuando se consultan y cuando se ayudan mutuamente para superar los retos y avanzar al siguiente nivel del juego.

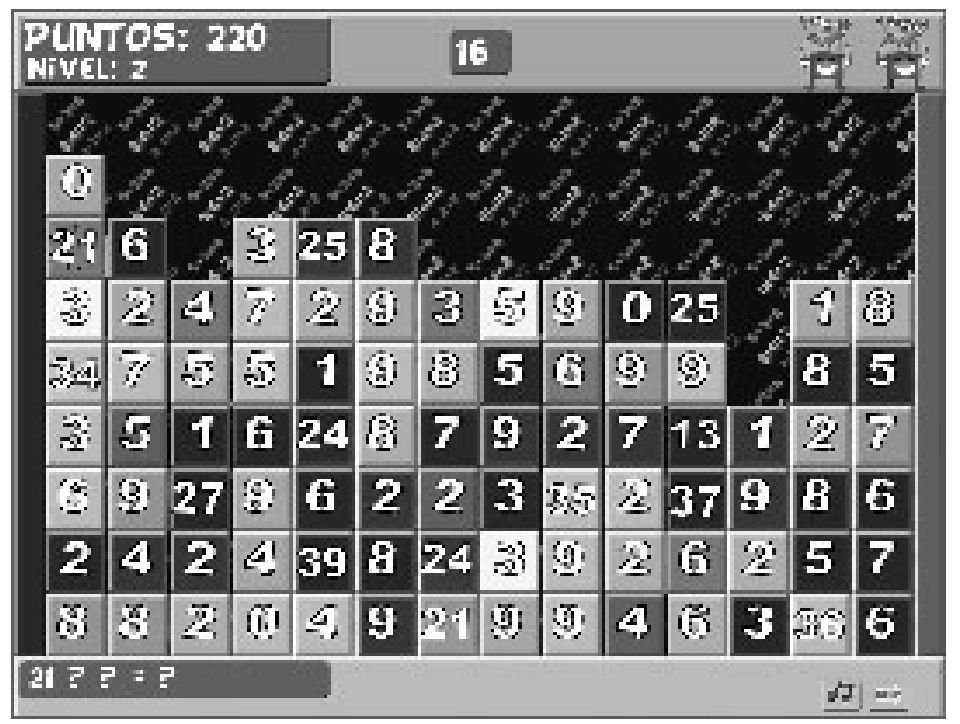

Corresponde aclarar que en el caso de los alumnos de Educación Inicial, al momento de efectuar el trabajo de campo de esta investigación aún no contaban con una XO propia. Por dicha razón, las maestras propusieron trabajo en talleres donde compartieron una única computadora: la de la maestra. En otras ocasiones los talleres se realizan con la participación de alumnos de grados superiores quienes comparten sus laptops y sus conocimientos con los de Nivel Inicial.

Asimismo existen videojuegos que presentan la opción de jugar en grupo. De esta forma se favorece la comunicación entre los niños, quienes comparten intereses, aprenden a trabajar en grupo y se hacen más sociables. De igual manera, a través de la actividad y la interacción se fomentan la curiosidad, la imaginación y la creatividad y se promueve la reflexión y el deseo de superación. Esto a su vez permite fortalecer el "aprender haciendo" y el intercambio entre pares y con los adultos, lo que lleva a la producción del conocimiento compartido y socialmente distribuido.

\section{Los juegos citados en la investigación}

Otra constatación fue la variedad de juegos utilizados por los docentes en sus clases. Se exploraron los juegos y los sitios de donde provienen los que nombran los docentes, tanto en las entrevistas como en las encuestas. De esa exploración se desprendió que:

- Una amplia gama de juegos citados han sido creados especialmente para descargar en la XO y en la mayoría de los casos son actividades difundidas en el Portal CEIBAL.

- Otros varios videojuegos nombrados por los docentes en la investigación son obtenidos por ellos por medio de la búsqueda libre en Internet. Los buscan por contenido y luego de realizar la exploración de los mismos determinan si pueden ser aplicados en sus clases y si se adecuan o no a los propósitos de enseñanza. 
A partir de los datos recabados se pudo realizar una clasificación primaria de los mismos:

- Juegos para descargar en la XO: "1811" (también llamado "Bicentenario"), "Conozco alimentos", "Conozco América", "Conozco Uruguay", "Constructor de historietas", "Detective Marciano", "División Especial de Detectives”, "Fotoaventura”, "Flipsticks”, "Gcompris”, "Hablar con Sara”, "Memorizar", "Nutrición”, "Salúdame”, "Sin dientes”, "Tetris Math”, "Tux Math".

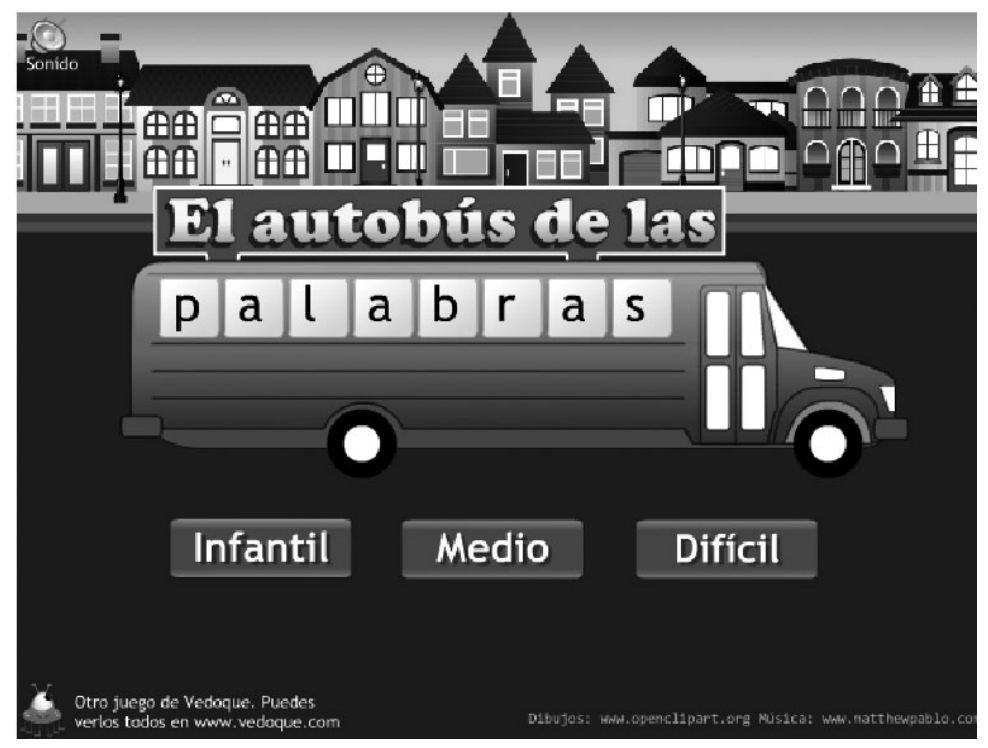

- Juegos que requieren conexión: "Cazaproblemas", "Más ciudadano", "MR2", "Suma tic", "Trivia”. Juegos en línea de sitios como "Súper Saber", "Educalandia”, "Genmagic", "Jueduland”, "Vedoque".

- Juegos que ofrecen ambas posibilidades: descarga o juego en línea. Entre ellos encontramos: "Ajedrez y leyendas”, "Piracálculos”, “¿Quién quiere ser millonario?”, “Tangram”.

En las entrevistas, los docentes realizaron descripciones de varios de los juegos que utilizan. Por ejemplo, una maestra describe el "Vedoque" de la siguiente manera:

"Son como tres juegos que hay con distintas actividades, como marcianitos, alegres, que a los niños les motiva, y tiene actividades donde ellos tienen que hacer una correspondencia entre el dibujo y la palabra. Tiene, también, para escribir en cursiva y tiene otros para formar palabras. El niño ya desde el comienzo del trabajo en la escuela aprende con ese tipo de juegos. Los niños con dificultad necesitan una motivación mayor...en estos casos, se las daba el juego..." (Entrevista 1 - Maestra 1 - Escuela I). Los Vedoque abarcan juegos de todas las áreas del conocimiento.

Al referirse al "Flipsticks", la Profesora de Educación Física en la entrevista expresó:

"Ellos tienen que tomarse el trabajo de analizar el movimiento, de pensar..., si el muñeco va a caminar, ¿qué hacemos para caminar, primero? ¿De dónde sale el movimiento de caminar? A ver, primero, levanta la rodilla, apoya el pie, ¿qué pasa con el otro? Como va sacando foto... después pones play y el niño camina solo. Si sale mal, ellos ponen play y el niño no va a caminar. Es súper difícil hacerlo caminar. Después le pido que el niño... o que haga la voltereta, o que haga el paro de manos. Entonces eso ya lleva a cierta interiorización de ese movimiento, como hacer consciente lo que yo hago de forma motriz" (Entrevista 2 - Profesora de Educación Física - Escuela V). 


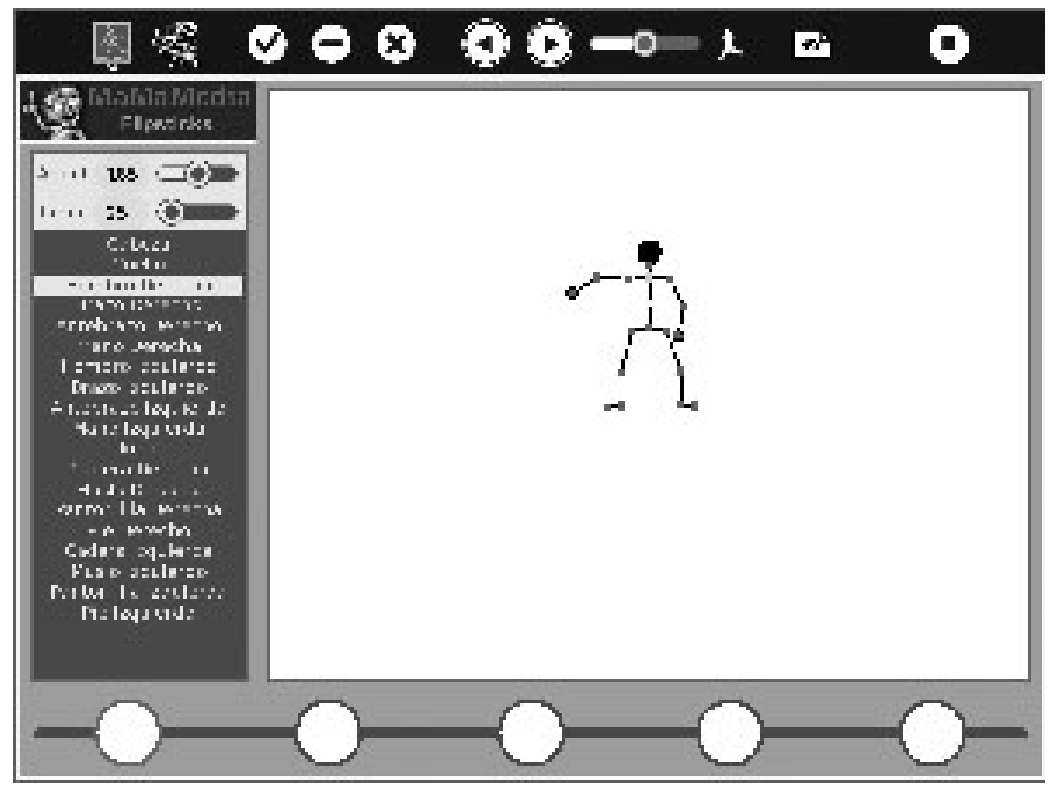

\section{Fortalezas y debilidades}

En este apartado se hace referencia a algunos aspectos que fueron señalados en la investigación por los docentes con respecto a la utilización de los videojuegos y de las XO, en general.

\section{Fortalezas}

Entre las fortalezas encontradas se destaca la infraestructura tecnológica: los avances en la conectividad, la implementación del Plan CEIBAL y la creación de los portales educativos uruguayos: el Portal CEIBAL y el Portal Uruguay Educa.

EI Plan CEIBAL ha logrado uno de sus objetivos principales: la democratización en el acceso a la información y la equidad de oportunidades, pues ha llegado a todos los hogares de los alumnos de escuelas públicas en una primera etapa, y, posteriormente, a los alumnos de Enseñanza Media Básica y a los de los últimos grados de Formación Docente. El Portal CEIBAL constituye un medio en línea donde docentes, alumnos y padres encuentran variados recursos didácticos y materiales curriculares, donde pueden llevar a cabo evaluaciones y actividades diagnósticas automatizadas, y que permite reunir datos relativos al rendimiento y efectuar seguimientos. En los portales antes mencionados se encuentran recursos que involucran el uso de juegos, a los que recurren con frecuencia algunos docentes de esta investigación.

Otra evidencia derivada de esta investigación es el hecho de que no se constata la existencia de "barreras psicológicas" ni rechazo a priori al uso de innovaciones, ni tampoco al uso de videojuegos en el proceso educativo. Al contrario, se aprecia una percepción positiva sobre estos últimos: el $68 \%$ de los docentes de la muestra entiende que influyen positivamente en el rendimiento escolar.

Asimismo se ha encontrado que los docentes con más años de trabajo son los que más se atreven a ensayar la aplicación de tecnologías digitales y, en particular, de videojuegos. Esto implica, por lo tanto, que no se detectó la existencia de "barreras generacionales". 


\section{Debilidades}

Como debilidades principales detectadas se pueden citar las siguientes: las laptops, los problemas de conectividad y la falta de formación en el tema por parte de los docentes.

En cuanto a las laptops entregadas por parte del Plan CEIBAL y a la conectividad, las quejas principales se resumen en las palabras expresadas por una maestra: "Pero no siempre hay cosas que sean buenas, y que se puedan ver bien. Por ejemplo, el uso de videos. La máquina es muy limitada en cuanto al uso del video, porque se corta mucho. O la conexión, que es lenta. Yo, en mi casa busco, con mi computadora un juego divino, precioso, que me encanta, funciona bárbaro, con movimiento y todo y después en la XO no funciona" (Maestra II - Escuela II). Respecto a las XO otra maestra en la entrevista manifiesta: "Empezamos, por ejemplo, con un $80 \%$ de las computadoras y luego que las encendemos empiezan a fallar, que una no se conecta, que la otra se tranca. Sí, hay mucho problema..." (Maestra II - Escuela III).

Otros problemas que se presentan a la hora de utilizar las XO y que influyen en la motivación de los docentes para su uso en las aulas son que no todos los niños las tienen porque están rotas o extraviadas, o se olvidan de llevarlas a clase, u olvidan cargarles las baterías. Varios docentes de la muestra consideran que deberían recibir una computadora mejor, pues la que tienen no siempre les permite realizar lo que han planificado a partir de la búsqueda en otras computadoras. Varios docentes manifestaron que intentaron usar la laptop que les fue entregada por el Plan CEIBAL pero debido al hecho de que presentan ciertas características como pantallas de tamaño reducido, teclado creado para niños pequeños y problemas de conectividad no logran un funcionamiento adecuado, lo que los lleva a la frustración y a perder el interés por su uso en el aula.

La falta de preparación específica en el tema de la aplicación de videojuegos en el aula es señalada, por algunos docentes, como una debilidad. Por tal motivo, en las encuestas algunos indican la necesidad de una capacitación específica en el uso pedagógico de videojuegos. Si bien en los portales educativos uruguayos se encuentran ejemplos y sugerencias para la utilización de los videojuegos en las prácticas de aula, varios docentes de esta investigación manifestaron que nunca ingresan a los portales, y por tal motivo no conocen esas propuestas.

La Evaluación oficial del Plan CEIBAL del año 2010 da cuenta de que ya en el año 2009 el $63 \%$ de los docentes había recibido algún tipo de capacitación. Sin embargo, a la fecha de la realización de la presente investigación se pudo comprobar que siguen existiendo docentes que no utilizan las TIC en su vida cotidiana, lo que hace muy difícil que sea normal su uso en las aulas. Un razonamiento similar puede aplicarse a la enseñanza con videojuegos.

Hace unos años era el maestro el que sabía usar todos los recursos tecnológicos. Actualmente todos sus alumnos cuentan con XO y más tiempo para explorar, para buscar juegos y jugar que el docente. Eso hace que el dominio tecnológico en el uso de la computadora de los alumnos sea muy superior al del docente. Como consecuencia, en una amplia mayoría, se sienten en inferioridad de condiciones con respecto a sus alumnos. Si, con mucho esfuerzo, logran apropiarse del funcionamiento de algún juego y lo presentan a sus alumnos, éstos se aburren porque son tan sencillos que no representan reto alguno. En contraposición, existen otros que los alumnos resuelven rápidamente y que sus maestros no logran entender. ¿Cómo pueden planificar en qué contenidos aplicar los juegos si no son capaces de usarlos? Antes, el docente tenía el poder cuando utilizaba un recurso tecnológico. En la actualidad, frente a las $\mathrm{XO}$, muchas veces ha perdido ese poder. 
A lo anterior debe agregarse otra debilidad: el hecho de que la innovación que supone la incorporación del Plan CEIBAL no partió de los propios docentes sino que procedió de las autoridades. Las innovaciones que tienen más posibilidades de éxito y continuidad son las que surgen de los propios docentes.

\section{Conclusiones}

Es muy elevado el porcentaje de los docentes de esta investigación (94\% de los encuestados) que consideran que el uso de los videojuegos permite el desarrollo de habilidades y competencias tales como agilidad mental, lectura, observación, creatividad, rapidez de respuesta, ampliación del vocabulario, capacidad de resolver problemas y planificación de estrategias, capacidad de orientación y para leer mapas, búsqueda de información, capacidades organizativas, comprensión, atención, memoria, razonamiento lógico, trabajo colaborativo y perseverancia.

El $34 \%$ de los docentes de la muestra manifiesta que utilizan muchas veces los videojuegos en sus clases. Generalmente los emplean dentro de proyectos o de secuencias de enseñanza.

Los docentes entrevistados, que constituyen el 16\% de la muestra, expresaron que emplean los videojuegos en diferentes escenarios que hemos denominado de construcción de conocimientos, de aplicación, de evaluación, de integración social y de recreación. Los propósitos con que los utilizan en sus clases son los de motivar, facilitar el aprendizaje, aplicar los conocimientos, evaluar y recrear.

En la Evaluación del año 2010 del Plan CEIBAL, "63\% de los docentes reconoce que la presencia de las computadoras XO les ha permitido plantearse cambios en la forma en que desarrollan sus prácticas de aula... en mayor medida en las áreas Social y de Lengua, luego en el área de Naturaleza y en cuarto lugar en Matemática" (ANEP, 2011, 33). En cambio, la presente investigación ha mostrado que la utilización mayor de los videojuegos es en Matemática (37\%), seguida de Conocimiento Social (26\%) y, en tercer lugar, Conocimiento de Lengua (18\%).

Los docentes señalaron una amplia gama de juegos, varios creados con la finalidad de que los alumnos los descarguen en las XO, y difundidos en el Portal CEIBAL.

Pero también el $52 \%$ de los docentes expresa que utilizan juegos de uno o de los dos portales uruguayos. Por otra parte, el $15 \%$ encuentra los videojuegos que emplean en sus aulas mediante la búsqueda libre que realizan en Internet, y el único criterio de búsqueda es el contenido a abordar.

Si bien reconocen habilidades y competencias que pueden favorecerse con el empleo de los videojuegos, en las encuestas algunos docentes manifestaron que no los usan por falta de capacitación en el uso de los mismos y, por tal motivo, expresaron la necesidad de tal capacitación.

De acuerdo con Analía Segal (2012), si un videojuego no está enmarcado en un escenario didáctico, no "produce" una clase. Solamente dentro de una planificación de contenidos bien secuenciados puede tener valor didáctico-pedagógico.

\section{Bibliografía}

ANEP (2011). Evaluación del Plan CEIBAL 2010. Documento Resumen. Documento IIIMontevideo.

ANEP (2011). Informe de Evaluación del Plan CEIBAL 2010. [en línea] Accedido el 20 de febrero, 2012, desde http://www.anep.edu.uy/anepdata/0000041447.pdf

ANEP/CEIP (2008). Programa de Educación Inicial y Primaria. Montevideo: Imprenta Rosgal S.A. 
ANEP/MECAEP (1997). Propuesta pedagógica para las escuelas de Tiempo Completo. [en línea] Accedido el 20 de febrero, 2012, desde http://www.cep.edu.uy/archivos/tiempocompleto/ pptc.pdf

BARTOLOMÉ, A. (1999). Nuevas tecnologías en el aula. Guía de supervivencia. Barcelona: Graó.

CURBELO, D. \& DA SILVA, M. Habilidades para la sociedad en red a partir del uso de videojuegos en las XO del Plan Ceibal. Trabajo presentado en las IX Jornadas de Investigación de la Facultad de Ciencias Sociales, UdelaR, Montevideo, 13-15 de setiembre de 2010. [en línea] Accedido el 10 de marzo, 2012, desde http://www.flordeceibo.edu.uy/files/CurbeloDaSilva-Videojuegos\%20FSC.pdf

FLICK, U. (2007). Introducción a la investigación cualitativa. 2a. Edición. Madrid: Morata.

GEYMONAT, N. (2012). ¿A qué jugamos hoy? Videojuegos en XO en seis escuelas de Tiempo Completo de Montevideo: de lo sociocultural a lo didáctico-pedagógico. Disponible en línea: http://bibliotecas.ort.edu.uy/bibid/75768/file/509

GROMPONE, J. (1993). Yo, Hombre. Tú, computadora. 2a ed. Montevideo: La flor de Itapebí. GROS, B. (2008). Videojuegos y aprendizaje. Accedido el 27 de octubre, 2012, desde http://books.google.com.uy/books?id=SeXhfWORMsgC\&pg=PA22\&num=9\&hl=es\&source=g bs_selected_pages\&cad=3\#v=onepage\&q\&f=false

LACASA, P. (1994). Aprender en la escuela, aprender en la calle. Madrid: Visor.

LACASA, P. (2011). Los videojuegos. Aprender en mundos reales y virtuales. Madrid: Morata.

LITWIN, E. (compiladora) (2009). Tecnologías educativas en tiempos de Internet. Buenos Aires - Madrid: Amorrortu Editores.

MARQUĖS, P. (2001). (Última revisión: 7/08/11) Los videojuegos. Accedido el 1 de diciembre, 2012, desde http://peremarques.pangea.org/videojue.htm

MOLINAS, I. Memoria de elefante: interrogantes sobre la incorporación de los videojuegos en la enseñanza. En: LITWIN, E. (compiladora) (2009). Tecnologías educativas en tiempos de Internet. Capítulo 4. Buenos Aires, Madrid. Amorrortu Editores.

MONTERO, E. \& RUIZ, M. \& DÍAZ, B. (2010). Aprendiendo con videojuegos. Jugar es pensar dos veces. Madrid: Narcea, S.A.

PISCITELLI, A. (2009). Aula XXI. Nativos digitales. Dieta cognitiva, inteligencia colectiva y arquitecturas de la participación. Uruguay: Santillana.

PRENSKY, M. (2001). Nativos digitales, Inmigrantes digitales. Accedido el 1 de diciembre de 2012, desde http://recursos.aprenderapensar.net/files/2009/04/nativos-digitales-parte1.pdf

SEGAL, A. (2012). Videojuegos en contexto de Aula. Accedido el 20 de noviembre, 2012, desde http://www.youtube.com/watch?v=vEl1YxEIrqA

VIDA, T. \& HERNÁNDEZ, T. (2008). Los videojuegos. Barcelona: Graó.

WOLF, M. \& PERRON, B. (2005) Introducción a la teoría del videojuego. Accedido el 20 de mayo de 2014, desde http://www.raco.cat/index.php/Formats/article/viewFile/257329/344420 


\section{Anexos}

Cuadro $N^{0}$ 1. Instrumento utilizado en el trabajo de campo: la encuesta

\begin{tabular}{|c|c|c|}
\hline 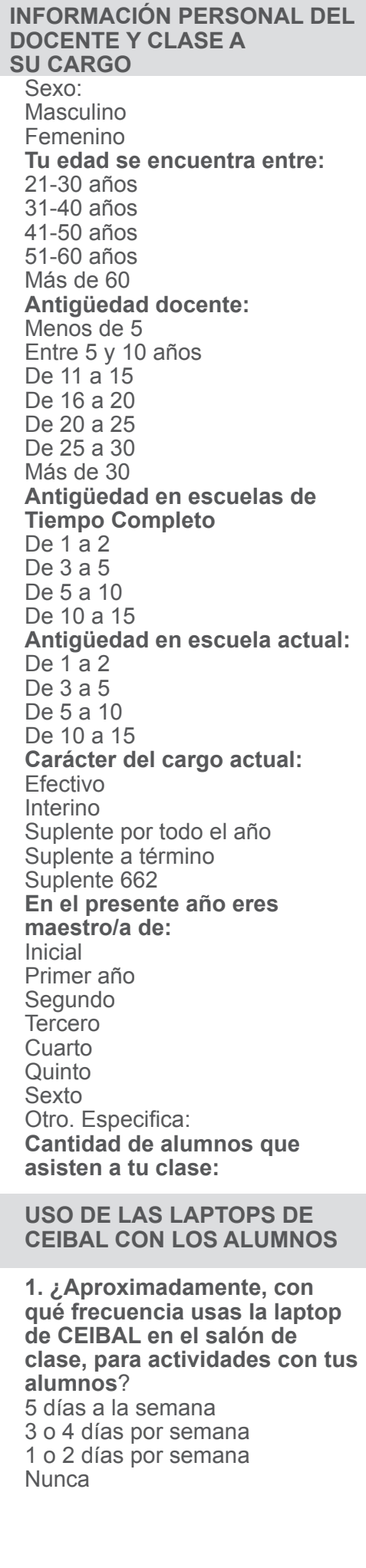 & 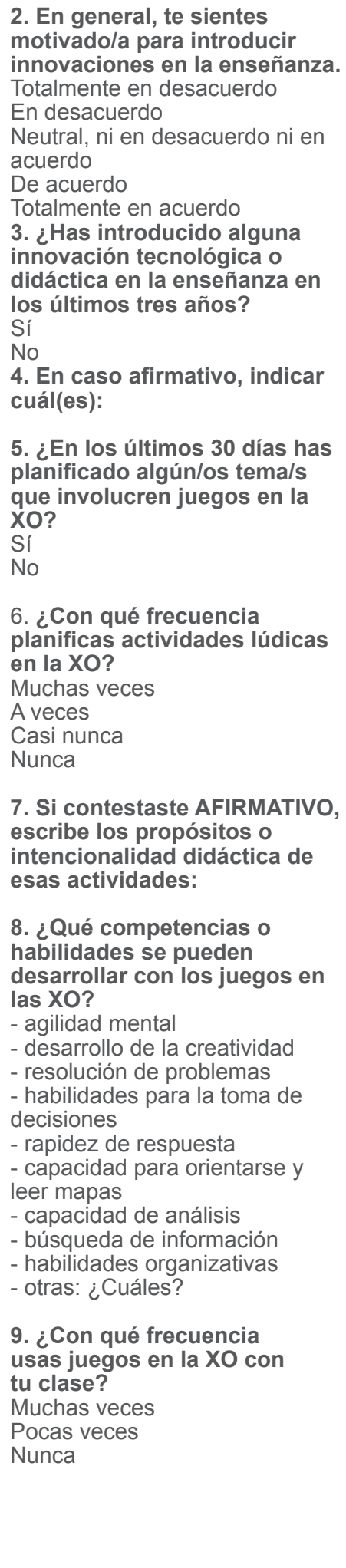 & 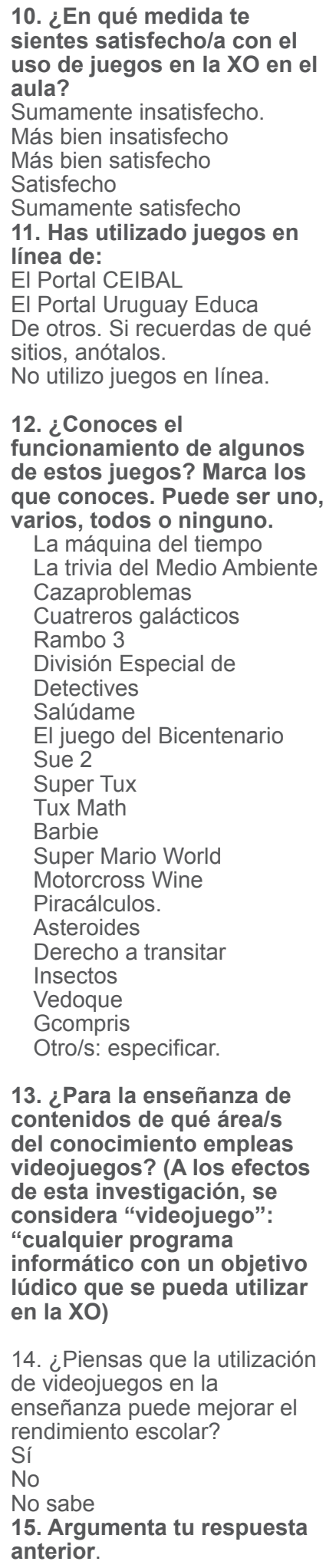 \\
\hline
\end{tabular}




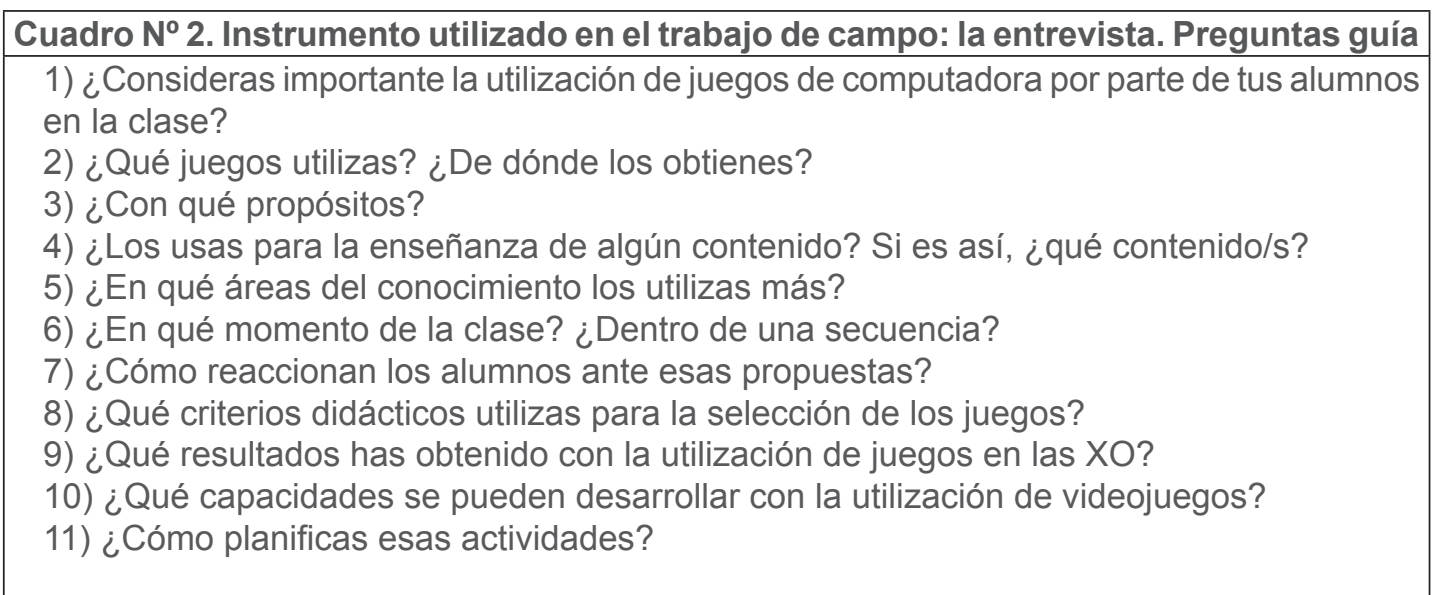

\section{Notas}

${ }^{1}$ Plan CEIBAL es un proyecto socioeducativo de Uruguay, creado por decreto de Presidencia de la República en el año 2007. Es un plan de inclusión tecnológica y social pues entrega una computadora a cada alumno que asiste a los centros de enseñanza pública.

${ }^{2}$ Hay distintos tipos de escuelas urbanas en Uruguay: Comunes, de Tiempo Completo, de Tiempo Extendido. En las escuelas de Tiempo Completo (TC) los niños permanecen diariamente siete horas y media (de 8:30 a 16:00 horas) http://www.oei.es/quipu/uruguay/Esc_tiempo_completo. pdf

${ }^{3}$ La Administración Nacional de Educación Pública (ANEP) es un ente autónomo con personería jurídica creado por la Ley $N^{0} 15.739$, de 28 de marzo de 1985 y funciona de conformidad con los Artículos 202 y siguientes de la Constitución de la República Oriental del Uruguay y de la Ley General de Educación. Sus cometidos son:

- Elaborar, instrumentar y desarrollar las políticas educativas que correspondan a los niveles de educación que el ente imparta;

- Garantizar la educación en los diferentes niveles y modalidades educativas de su competencia a todos los habitantes del país, asegurando el ingreso, permanencia y egreso;

- Asegurar el cumplimiento de los principios y orientaciones generales de la educación establecidos en la presente ley en los ámbitos de su competencia;

- Promover la participación de toda la sociedad en la formulación, implementación y desarrollo de la educación en la órbita de su competencia.

Los órganos que integran la ANEP son los siguientes: el Consejo Directivo Central, los Consejos de Educación Inicial y Primaria, Consejo de Educación Secundaria, Consejo de Educación Técnico-Profesional (UTU) y el Consejo de Formación en Educación.

Fuente: http://www.anep.edu.uy/anep/index.php/acerca-de-anep

${ }^{4}$ El Monitor Educativo proporciona información sistematizada acerca de las escuelas públicas en Uruguay. Lo realiza el Departamento de Estadística Educativa del Consejo de Enseñanza Inicial y Primaria (CEIP), en base a la información proporcionada al finalizar el año anterior en cuanto a matrícula, promedio de alumnos por grupo, repetición, abandono intermitente, asistencia insuficiente, antigüedad docente y estabilidad docente en la escuela. Las escuelas se agrupan en cinco niveles (Quintil 1 a 5), de modo que el Quintil 1 agrupa el 20\% de escuelas de contextos más vulnerables, el Quintil 2, el siguiente 20\% y así hasta el Quintil 5 que agrupa las escuelas de menor vulnerabilidad. http://www.anep.edu.uy/monitor/servlet/buscarescuela 